\title{
ANALISIS KEBUTUHAN PENGEMBANGAN JOB SHEET PADA MATAKULIAH PEMROGRAMAN BERORIENTASI OBJEK
}

\author{
Nurindah Dwiyani ${ }^{1}$ \\ Yeka Hendriyani ${ }^{2}$ \\ Vera Irma Delianti ${ }^{3}$
}

\begin{abstract}
The purpose of this article is to analyze the needs of developing the worksheet in the Object Oriented Programming (PBO) course. This research is explorative descriptive research. The subjects of this study are students of Electronics Engineering class of 2016 Faculty of Engineering, State University of Padang. Samples were randomly selected by 20 students. Data were collected using observation sheet of PBO lecture and student questionnaire. The result of the observation indicates that the current worksheet is too wide in the scope of the material because of the combination of the PBO 1 and PBO 2 job sheets and the lack of explanation of the statements on the soure code. The results of the questionnaire development needs of the development of the worksheet show that students need a more easily understood job sheet, equipped with success indicators and glossary of terms or functions in the PBO (Java Programming Language).
\end{abstract}

Keywords : Needs Analysis, Development of Learning Media, Job sheet, PBO

\section{INTI SARI}

Tujuan artikel ini adalah untuk menganalisis kebutuhan pengembangan job sheet pada matakuliah Pemrograman Berorientasi Objek (PBO). Penelitian ini adalah penelitian deskriptif ekploratif. Subjek penelitian ini adalah mahasiswa jurusan Teknik Elektronika angkatan 2016 Fakultas Teknik Universitas Negeri Padang. Sampel dipilih secara acak sebanyak 20 mahasiswa. Data dikumpulkan dengan menggunakan lembar observasi proses perkuliahan PBO dan angket mahasiswa. Hasil observasi menunjukan bahwa job sheet yang digunakan sekarang ini terlalu luas cakupan materinya karena gabungan dari job sheet PBO 1 dan PBO 2 dan kurangnya penjelasan dari statement-statement pada sourecodenya. Hasil analisis angket kebutuhan pengembangan job sheet menunjukan bahwa mahasiswa membutuhkan job sheet yang lebih mudah dipahami, dilengkapi dengan indikator keberhasilan serta glosarium istilah-istilah atau fungsi dalam PBO (Bahasa Pemrograman Java).

Kata Kunci : Analisis Kebutuhan, Pengembangan Media Ajar, Job sheet, PBO 


\section{PENDAHULUAN}

Pendidikan yang menjadi pondasi kuat berkembangnya suatu negara adalah pendidikan yang bermutu. (Suderadjad, 2005 : 17) menyatakan bahwa "pendidikan bermutu adalah pendidikan yang mampu menghasilkan lulusan yang memiliki kemampuan atau kompetensi, baik kompetensi akademik maupun kompetensi keguruan, yang dilandasi oleh kompetensi personal dan sosial, serta nilai - nilai akhlak mulia, yang keseluruhanya merupakan kecakapan hidup, lebih lanjut Sudradjat megemukakan pendidikan bermutu adalah pendidikan yang mampu menghasilkan manusia seutuhnya (manusia paripurna) atau manusia dengan pribadi yang integral (integrated personality) yaitu mereka yang mampu mengintegralkan iman, ilmu, dan amal. Dengan demikian kegiatan belajar mengajar hendaknya sejalan dengan motivasi dan sasaran belajar, sehinga tujuan pembelajaran dapat dikuasai secara optimal sesuai dengan perkembangan teknologi dan informasi.

Pada era sekarang pelaksanaan pendidikan tidak dapat terlepas dari perkembangan ilmu pengetahuan dan teknologi (IPTEK). Salah satu perkembangan IPTEK yang juga merambah ke dunia pendidikan adalah penggunaan komputer. Keberadaan komputer menggantikan penggunaan mesin ketik konvensional. Lewat perangkat lunak (software) yang terpasang di dalamnya, komputer dapat melakukan aplikasi untuk berbagai keperluan penggunanya (user). Komputer juga memberikan dampak positif dalam pembelajaran.

Salah satu mata kuliah yang menggunakan komputer dalam proses pembelajarannya adalah Praktikum Pemrograman Berorientasi Objek (PBO). PBO merupakan paradigma pemrograman yang berorientasikan kepada objek. Semua data dan fungsi di dalam paradigma ini dibungkus dalam kelas-kelas atau objek-objek. Bandingkan dengan logika pemrograman terstruktur. Setiap objek dapat menerima pesan, memproses data, dan mengirim pesan ke objek lainnya (Sholiq 2006).

Tujuan penelitian ini adalah untuk mengetahui bahan ajar yang perlu dikembangkan pada matakuliah PBO. Hasil penelitian ini diharapkan dapat memberikan informasi mengenai bahan ajar yang perlu dikembangkan pada matakuliah PBO yang dapat meningkatkan pemahaman dan dapat dipelajari secara mandiri oleh mahasiswa

\section{PENDEKATAN PEMECAHAN MASALAH}

\section{METODE PENELITIAN}

Penelitian ini merupakan penelitian deskriptif eksploratif yang dilaksanakan pada bulan Agustus s.d. September 2017 di Universitas 
Negeri Padang. Subjek penelitian adalah mahasiswa D3 Teknik elektronika angkatan 2016 Fakultas Teknik Universitas Negeri Padang. Sampel dipilih secara acak sebanyak 20 mahasiswa. Data dikumpulkan dengan menggunakan lembar observasi proses perkuliahan PBO dan angket.

Lembar observasi analisis kebutuhan pengembangan bahan ajar berisi pertanyaan-pertanyaan sebagai berikut.

a. Berdasarkan pandangan dan pengamatan selama praktikum PBO, bagaimana reaksi mahasiswa terhadap proses pembelajaran di Labor?

b. Hal apa saja yang menjadi kendala dalam praktikum PBO?

C. Bagaimana strategi perkuliahan yang diterapkan pada perkuliahan praktikum PBO?

d. Apa sajakah bahan belajar yang telah digunakan praktik PBO

e. Apa saja cakupan materi pada praktikum PBO

Adapun angket analisis kebutuhan pengembangan bahan ajar untuk mahasiswa berisi

pertanyaan sebagai berikut.

a. Sumber belajar apa sajakah yang saudara gunakan untuk mempelajari perubahan praktikum $\mathrm{PBO}$ ?

b. Bagaimana sumber belajar yang saudara inginkan untuk menunjang pembejaran praktikum $\mathrm{PBO}$ ?

c. Bagaimana strategi perkuliahan yang diterapkan pada perkuliahan praktikum $\mathrm{PBO}$ ?

d. Apakah job sheet yang saudara gunakan saat ini disertai dengan gambar-gambar menarik dan mudah dipahami?

e. Apa saran saudara untuk pengembangan bahan ajar agar mudah memahami PBO?

\section{HASIL DAN PEMBAHASAN}

Berdasarkan observasi dan pengamatan selama praktikum PBO, reaksi mahasiswa terhadap proses pembelajaran di labor masih kurang antusias. Hal yang menjadi kendala selama praktikum PBO antara lain partisipasi mahasiswa selama

perkuliahan masih kurang, mahasiswa hanya mencobakan program yang ada tanpa melakukan analisa atau hanya copy - paste saja, cakupan materi job sheet yang digunakan saat ini terlalu luas. Strategi perkuliahan yang diterapkan pada praktikum PBO yaitu mahasiswa mencobakan job sheet yang ada tanpa memahami listing programnya karena ada 18 job sheet yang harus diselesaikan dalam satu semester. Dosen pengampu matakuliah Praktikum PBO juga setuju untuk mengembangkan job sheet yang sesuai dengan waktu dan materi yang paling essensial sehingga bisa menuntun mahasiswa untuk belajar mandiri. Pustaka yang digunakan dalam job sheet PBO selama ini hanya dari modul JENI yang cakupan materinya sangat luas untuk deselesaikan dalam waktu satu semester.

Hasil analisis angket kebutuhan pengembangan bahan ajar menunjukkan bahwa mahasiswa menginginkan sumber belajar yang dibuat sendiri oleh dosen, menggunakan bahasa Indonesia yang mudah dimengerti dan dipahami, berupa ringkasan yang bisa menarik minat baca mahasiswa, serta dilengkapi dengan gambar- 
gambar penunjang. Strategi perkuliahan yang diterapkan selama ini yaitu praktikum laboratorium dan hanya copy - paste. Sumber belajar yang digunakan selama ini kurang menarik karena tidak ada penjelasan rinci dari masing-masing program percobaan atau latihan. Mahasiswa menyarankan agar dikembangkan job sheet yang runtut, materi singkat, dan ada penjelasan yang detail dari contoh-contoh program yang diberikan sehingga bisa dikembangkan dengan kasus yang lain. Penggunaan media pembelajaran merupakan salah satu faktor penting dalam poses pembelajaran karena dapat memotivasi siswa untuk aktif dan berkontribusi positif dalam proses pembelajaran. Gagne (1970) dalam Sadiman dkk (2010) menyatakan bahwa media adalah berbagai jenis komponen dalam lingkungan siswa yang dapat merangsangnya untuk belajar. Sementara itu, Briggs (1970) dalam Sadiman dkk (2010) berpendapat bahwa media adalah segala alat fisik yang dapat menyajikan pesan serta merangsang siswa untuk belajar. Berdasarkan data hasil penelitian, maka perlu dikembangkan media pembelajaran job sheet. Job sheet adalah alat pendidikan yang dicetak yang digunakan untuk mendukung seorang instruktur dalam pengajaran keterampilan terutama di workshop, yang di dalamnya berisi seperangkat pengarahan dan gambar tentang bagaimana cara membuat atau menyelesaikan pekerjaan. Job sheet dipilih karena dapat memfasilitasi mahasiswa untuk belajar, baik dengan pendidik maupun secara mandiri. Media pembelajaran job sheet juga bersifat self contained dan self instruction, yaitu pembelajaran mandiri. Job sheet merupakan salah satu bahan ajar yang dirancang secara sistematis berdasarkan kurikulum tertentu dan dikemas dalam bentuk satuan pembelajaran terkecil dan memungkinkan dipelajari secara mandiri dalam satuan waktu tertentu (Purwanto, dkk., 2007). (Santyasa, 2009 : 9) juga menyatakan bahwa strategi pengorganisasian materi pembelajaran pada modul mengandung squencing yang mengacu pada pembuatan urutan penyajian materi pelajaran, dan synthe sizing yang mengacu pada upaya untuk menunjukkan kepada peserta didik keterkaitan antara fakta, konsep, prosedur dan prinsip yang terkandung dalam materi pembelajaran. Sistem pembelajaran dengan menggunakan job sheet akan menjadikan pembelajaran berlangsung lebih efektif, efisien dan relevan (Wena,2009). Pembelajaran dengan menggunakan job sheet bersifat pembelajaran mandiri yang memberikan kesempatan kepada mahasiswa untuk mengelola waktu belajarnya dan memahami materi perkuliahan secara mandiri.

\section{KESIMPULAN}

Berdasarkan data hasil penelitian dapat disimpulkan bahwa job sheet matakuliah PBO di Jurusan Teknik Elketronika Fakultas Teknik Universitas Negeri Padang perlu dikembangkan. Job sheet dipilih karena dapat memfasilitasi mahasiswa untuk belajar, baik dengan pendidik maupun secara mandiri. Perancangan job sheet mata kuliah PBO ini bertujuan untuk sebagai media pembelajaran yang bisa digunakan mahasiswa untuk melaksanakan praktikum dengan lebih mudah dan terarah serta bisa dikerjakan secara mandiri diluar jam praktikum. Sehingga mahasiswa Jurusan Teknik Elektronika Fakultas 
Teknik UNP bisa lebih mendalami bahasa pemrograman dengan lebih mudah.

\section{DAFTAR PUSTAKA}

[1] Gagne RM. 1970. The Conditions of Learning. New York: Holt, Rinehart and Winston.

[2] I Wayan dkk, Pengembangan EModul Berbasis Project Based Learning Pada Mata Pelajaran Pemrograman Berorientasi Objek Kelas XI RPL di SMK Negeri 2 Tabanan. Jurnal Janapati Vol.6 No.2 Juli 2017. Diakses tanggal 2 November 2017

[3] Ngalim Purwanto. 2007. Psikologi Pendidikan. Bandung: PT Remaja Rosdakarya.
[4] Santyasa, I. W. (2009). Teori Pengembangan Modul. Bali: Universitas Pendidikan Ganesha.

[5] Sholiq, 2006. Pemodelan Sistem Berorientasi Objek dengan UML : Graha IImu

[6]Suderadjad, H. (2005). Manajemen Peningkatan Mutu Berbasis Sekolah; Peningkatan Mutu Pendidikan Melalui Implementasi KBK. Bandung: Cipta Lekas Garafika, 17.

[7] Wena, M. (2009). Strategi Pembelajaran Inovatif Kontemporer (Suatu Tinjauan Konseptual Operasional). Jakarta: Bumi Aksara. 